\title{
The Economic Impact of Bariatric Surgery
}

\author{
Anke-Peggy Holtorf ${ }^{1,2}$, Harald Rinde ${ }^{2}$, Frederic Rupprecht ${ }^{3}$, \\ Henry Alder ${ }^{3}$ and Diana Brixner ${ }^{1}$ \\ 1 University of Utah, \\ ${ }^{2}$ BioBridge Strategies LLC, \\ ${ }^{3}$ Ethicon Endosurgery \\ 1,3USA, \\ ${ }^{2}$ Switzerland
}

\section{Introduction}

It is estimated that $5.7 \%$ of American adults, or approximately 14.5 million people, are morbidly obese, defined as a body mass index (BMI) of $>40 \mathrm{~kg} / \mathrm{m}^{2}$ and thus are eligible for bariatric surgery. (Flegal et al. 2010) If in one year, only $10 \%$ of these morbidly obese patients (approximately 1.45 Million) would undergo bariatric surgery, with an average expenditure of approximately $\$ 20,000$, this would result in a total cost of US\$ 29 billion. This amount is equivalent to about $1 \%$ of the total healthcare expenditure in the USA.(National Health Expenditure Data 2011) This estimate most likely underestimates the potential cost because the obesity epidemic is still growing in the USA, which has an obesity rate of over $30 \%$.(Aasheim and Søvik 2011; Finucane et al. 2011; Flegal et al. 2010; Shao and Chin 2011) Because of the potentially significant impact on overall healthcare expenditures, policy makers and payers are very careful to allow free access to bariatric surgery for all severely or morbidly obese patients. In addition to appraising the impact on the future health status of morbidly obese patients, payers and decision makers want to be able to estimate the impact of bariatric surgery on their budgets and resources as well as to understand the potential return on such an investment. To determine the most recent knowledge on the economic consequences relating to bariatric surgery for payers in different healthcare settings, a literature review of economic or outcome publications was conducted and is summarized in this book chapter.

Short-term cost is often a major barrier to payers and other interested parties. Understanding the full cost consequences of bariatric surgery includes consideration and comparison of both conventional treatment and surgery for morbid obesity against the associated overall health outcome. This information is needed to make rational decisions. Nonsurgical approaches to weight loss, however, are often requested or even reimbursed before agreeing to surgery - despite the fact that the impact of these therapies has been shown to be modest and short term for most patients. (Bockelbrink et al. 2008; Picot et al. 2009; Li et al. 2005; Snow et al. 2005) To allow a rational decision, it is important to assess how bariatric surgery impacts health outcomes in comparison to the best existing alternatives and how much total expenditure is generated by bariatric surgery in comparison to the alternative approaches to weight loss. 


\subsection{Short introduction to health economics}

This section gives a brief introduction to health economics relevant to this chapter. Those familiar with health economics can skip this introduction.

Cost-effectiveness analysis is an attempt to answer the question: "How much more (than today) are we willing pay for an improvement in health outcomes?" Improvements in health outcomes include a gain of life years, a reduction of disability or an improvement in the quality of life. In the cost-utility analysis, clinical and humanistic parameters are combined as quality adjusted life years (QALY) and the cost to improve the outcome by one QALY is calculated. (Berger and International Society for Pharmacoeconomics and Outcomes Research 2003)

A QALY is a measure of additional life-time gained by a medical intervention (which could be a drug, surgery, diagnostic, etc.) adjusted by the utility or quality of life of the patients. The utility is evaluated through standardized and validated questionnaires (which can be general quality of life questionnaires or tailored to specific diseases) and quantified by health utilities or quality of life indices. These range from 1, a perfect state of health, to 0 , equivalent to death. QALYs are determined by multiplying the number of additional life years by the health utilities (for example, 4 years with a utility of $0.75=3$ QALYs). Cost-utility analysis allows comparing a broad range of healthcare interventions for their cost-utility and consequently help setting healthcare investment priorities. The incremental costeffectiveness or cost-utility ratios (ICER or ICUR) how much more has to be spent for a new technology over the comparator (usually the current standard of care) to achieve one additional QALY. (Berger and International Society for Pharmacoeconomics and Outcomes Research 2003)

Authorities in some countries, such as UK, Canada, Australia and Sweden, are using the incremental cost per QALY for making decisions on the degree of reimbursement for interventions. Theoretically, interventions achieving improved outcomes at lower total healthcare cost are dominant and should be used and reimbursed; interventions with a worse outcome at higher cost should never be reimbursed. For technologies which result in increased cost but produce better outcomes, there should be an agreed upon threshold of acceptable cost per QALY or cost-utility ratios. This threshold varies and is subject of many discussions, but usually lies around 1 to 3 times the gross domestic product per capita. (Landa 2008; Shiroiwa et al. 2010) Technologies with higher cost per QALY should not be reimbursed as a general rule. However, other factors are also taken into consideration when deciding whether to reimburse or not (e.g. local economy, culture, ethics, innovation factor, budget impact, others). In other countries, such as the USA, France or Germany, the cost per QALY is not generally considered a key decision criterion. In these countries, costeffectiveness or budget impact over a limited time period might be considered more important by payer decision makers.

Another way to estimate the value of bariatric surgery is to calculate the return on investment (ROI). ROI is a measure used to evaluate the efficiency of the investment in the surgery and is calculated for a defined time span by dividing the net financial gain (dollars gained from surgery minus the cost of surgery) by the cost of surgery. 


\section{Economic outcomes of bariatric surgery}

The general agreement is that patients with a BMI $>40 \mathrm{~kg} / \mathrm{m}^{2}$, or with a BMI $>35 \mathrm{~kg} / \mathrm{m}^{2}$ and a serious obesity-related comorbidity, who have failed to respond to conservative treatment (diet, exercise, pharmacology) are eligible for bariatric surgery. Despite this, less than $2 \%$ of these patients actually are offered or choose bariatric surgery. (Kim, White, and Buffington 2010) A core question to payers before extending access to bariatric surgery will be what impact the increased use of bariatric surgery will have on their overall budgets. (Powers, Rehrig, and Jones 2007)

\subsection{Cost associated with obesity and bariatric surgery}

The key cost components of obesity are:

- The need for ongoing dietary and behavioral interventions.

- Treatment of the health consequences of obesity such as type 2 diabetes and cardiovascular disease.

- Decreased work productivity.

- Increased overall cost of living (e.g., additional services needed because of decreased mobility, adaptation of articles of daily use or furniture, etc.).

The substantial health and quality of life benefits of decreased weight have been described in other chapters in this book. The question is whether the decreased costs of obesity listed above offset the cost of bariatric surgery, which is perceived as a costly procedure. The key cost components of surgery are (1) the surgical procedure and the associated hospital stay, (2) potentially serious short term and long term complications (e.g. surgical risk, food intolerance and micronutrient deficiencies, surgery related mortality), (3) supportive care services and treatments, and if necessary, potential reversal surgery.

\subsubsection{Cost of obesity}

Many studies have shown that obesity is associated with increased mortality, decreased quality of life, increased disability, and increased healthcare costs. (Finkelstein et al. 2009; Pendergast et al. 2010; Cawley 2010) The amount of this increase is different across different countries as shown by the following studies. Finkelstein et al estimated obesity-related diseases to account for $\$ 147$ billion in the USA in 2006. The same study showed that the rate of obesity in the US increased by 37\% from 1998 to 2006 with an increase of $89 \%$ in money spent on obesity-related diseases. This resulted in an increase from $6.5 \%$ to $9.1 \%$ of the total US healthcare budget spent on obesity and obesity related diseases. Finkelstein et al. calculated the adult annual per capita medical spending attributable to obesity (compared to a normal weight population) was $\$ 1,429$ (42\% higher than non-obese cost per capita). (Finkelstein et al. 2009) Significantly higher estimates of increased healthcare spending due to obesity were obtained by Pendergast et al. who calculated the annualized healthcare utilization costs for the US and Germany and found that in the US obese patients spent $73 \%$ more than non-obese people ( $\$ 4,780$ more) and 59\% more in Germany ( $\$ 1,035$ more). (Pendergast et al. 2010) Cawley et al. estimated that obesity raises annual medical costs by $\$ 2,826$ (2005 dollars) per obese patient and that the total annual cost of treating obesity in the US adult non-institutionalized population was $\$ 168$ billion, or $16.5 \%$ of national spending on medical care. (Cawley 2010) Future trends exacerbate the problem. 


\subsubsection{Cost of bariatric surgery}

\subsubsection{Cost of surgery procedure}

The cost of bariatric surgery has been estimated in several countries and from diverse perspectives. A summary of the cost estimates is listed in Table 1. For example for laparoscopic gastric banding (LAGB) the reported cost of surgery ranges from US\$7,125 in the UK to US\$25,000 in the US. The total short and long term cost of obesity or bariatric surgery is influenced by several factors, such as the cost of the intervention, the cost of adaptations (e.g. band adjustment) adverse events, reversals, nutritional supplements, secondary health-related cost such as treating the consequences of the fast and extensive weight loss, and cost of the general supportive care (e.g., dietary, educational, psychosocial). There is high variability amongst the existing studies as to which cost had been considered. A study in the UK estimated the immediate direct medical cost in the first year of LAGB to be $£ 4,750(\$ 7,125)$. In this study, conventional obesity therapy was calculated to be $£ 336$ (US\$500) in the first year. (Clegg et al. 2002) A year later, the same authors compared the direct medical cost of two types of surgery by calculating the direct medical cost over 20 years $\left(£ 10,795\right.$ for LAGB and $£ 9,627$ for vertical gastric banding $\left.(\mathrm{VBG})^{1}\right)$ with conventional care $(£ 6,964)$. (Clegg et al. 2002)

Some cost factors that have strongly affected the surgery-related cost for gastric banding in the early years, e.g. regular readjustment of the gastric band in the hospital, have been decreasing with greater experience and further development of the technology. Increasingly, the adjustments can now be performed during the regular visits in the outpatient setting, without the need for high cost hospital interventions. (Jan et al. 2007)

\subsubsection{Cost offset of usual care for those not receiving surgery}

It is crucial to consider, in addition to the immediate intervention-related cost, the cost from the longer-term consequences of obesity, such as type 2 diabetes mellitus, hypertension, cardiovascular diseases and increased cancer risk, in addition to reduced work productivity. For example, Ackroyd et al. published a model for bariatric surgery projected over five years for patients with type 2 diabetes in UK, France or Germany. (Ackroyd et al. 2006) The five-year cost of adjustable gastric banding in Germany was $€ 13,610$, in UK $€ 12,838(£ 9,072)$ and in France $€ 14,796$. While in UK the five-year direct medical cost of conventional care was lower than the surgical interventions $(£ 7,080$ equivalent to $€ 10,030)$, in both Germany and France the cost for usual care exceeded that of the surgical interventions (€17,197 and $€ 19,267$ respectively). This modelling study focused on patients with diabetes and incorporated all direct medical cost from third party payers' perspective. Thus, the conventional treatment cost not only included the cost for diet and exercise therapy but also the treatment of comorbidities and office visits during the five-year time frame in this patient segment (see Table 1). This model was based on the conservative assumption that the length of stay after LAGB would be five days. In newer research, this time is much shorter (Jan et al. 2007). This means that this study probably overestimates the cost of LAGB.

${ }^{1} £ 10,000$ would be equivalent to $€ 15^{\prime} 800$ or US $\$ 15,000$ 


\begin{tabular}{|l|c|c|c|}
\hline Publication & Data Year & Cost & Country \\
\hline Salem, 2008 & 2004 & $\$ 16,200$ & USA \\
\hline Paxton, 2005 & Before 2005 & $\$ 17,660-\$ 29,443$ & USA \\
\hline Livingston, 2005 & $2001 / 2002$ & $\$ 19,794-\$ 23,355$ & USA \\
\hline Ikramuddin, 2009 & 2007 & $\$ 19,760$ & USA \\
\hline Hoerger, 2010 & 2005 & $\$ 15,536-\$ 20,326$ & USA \\
\hline Chang, 2011 & 2010 & $\$ 23,778-\$ 64,784$ & USA \\
\hline Clegg, 2003 & Before 2001 & $£ 9,627-£ 10,795$ & UK \\
\hline Ackroyd, 2006 & $1998-2003$ & $£ 7,088-£ 9,121$ & UK \\
\hline Ackroyd, 2006 & $1998-2003$ & $£ 12,166-€ 17,197$ & GER \\
\hline Ackroyd, 2006 & $1998-2003$ & $€ 13,399-€ 19,276$ & FRA \\
\hline
\end{tabular}

Table 1. Summary of publications reporting cost of bariatric surgery.

Salem et al calculated the three-year cost of LAGB at US\$16,200 and for Roux-en-Y gastric bypass (RYGB) at US $\$ 27,560$, based on 2004 hospital charges associated with the surgery, including procedural fees, treatment of postoperative complications, follow-up care, and treatment of obesity-related diseases, such as coronary heart disease, stroke, type 2 diabetes, hypercholesterolemia, and hypertension.

More recent publications estimate an additional cost of US\$15,000 - US\$20,000 over the 3238 years after surgery. (Ikramuddin et al. 2009; Hoerger et al. 2010) Chang et al differentiated between patients with obesity related diseases (ORD) and those without ORDs and analyzed the cost for three BMI classes, BMI above 35 and below 40, BMI between 40 and 50, and BMI above 50kg/ $\mathrm{m}^{2}$. (Chang, Stoll, and Colditz 2011) Bariatric surgery in patients without ORDs incurred higher incremental cost over conventional therapy than in patient who had ORDs. In addition, the authors found that the incremental cost diminished with increasing BMI. This may be explained by the positive impact of bariatric surgery on ORDs, which lead to a prevention of costs related to the ORDs. On the other hand, higher BMI is a risk factor for developing ORDs and therefore, the total incremental cost of bariatric surgery as compared to non-surgery decreases with higher BMI.

\subsection{Cost and outcomes of bariatric surgery depending on the hospital's experience}

The more experienced the care team is the lower the cost of bariatric surgery. Nguyen et al compared bariatric surgery (Roux-en-Y gastric bypass) performed at low volume hospitals (less than 50 procedures per year) with high volume hospitals (more than 100 procedures per year). They found that high volume hospitals had shorter length of stay (3.8 days vs. 5.1 days for low volume hospitals), lower overall complications (10.2\% vs. $14.5 \%)$ and lower cost $(\$ 10,292$ vs. $\$ 13,908)$, (Nguyen 2004) which was driven to a large extent by the shorter hospital stay. The reduction of time in the hospital depends on the success rate of surgery 
and the avoidance of complications. (Encinosa 2009) Since hospital cost is a major driver in the overall cost of surgery, a reduction in the length of stay leads to an improved costeffectiveness ratio.

Increased improvement in the efficiency of surgery will improve the cost-utility ratio. For example, Jan et al. found in their retrospective analysis of data of a US hospital (in the high volume or Center of Excellence category) an average length of stay for LAGB of 1.1 days, while the time assumed in earlier models, or in studies integrating both open and laparoscopic adjustable gastric bypass, was more than 3 times as much. (Jan et al. 2007) As in the example of Ackroyd's analysis of surgery for diabetic patients, better patient profiling may also improve the cost-effectiveness ratio with improved targeting of the intervention and consequently, improved outcomes. (Ayckrod 2006)

\subsection{Cost-effectiveness of bariatric surgery}

When assessing the cost impact of bariatric surgery, it is important to compare the surgery related cost versus the cost consequences of obesity over time. The resulting cost difference can be assessed in relation to the desired outcomes, such as the length of life and the health related quality of life of the patients.

Ikramuddin et al. prospectively collected outcomes data in a practical real-life setting from 567 obese patients with type 2 diabetes that underwent Roux-en-Y gastric by-pass surgery between 2001 and 2007 at the University of Minnesota Medical Center, Minneapolis. The data was entered into a health economic model (CORE Model). (Ikramuddin et al. 2009) In the model, the patient data was compared to a standard population of obese diabetic patients based on data obtained from the United Kingdom Prospective Diabetes Study (UKPDS), and the Framingham Heart Study. (Palmer et al. 2004a,b) At baseline, the patients were on average 50.1 years old, had a mean duration of diabetes or pre-diabetes of 8.7 years and $77.9 \%$ were female. The model projected cost and outcome over a time period of 35 years and predicted that, after discounting cost and outcomes, patients that had bariatric surgery would on average live 11.54 years (undiscounted 15.94 years), while those only treated with conservative medical intervention would survive on average 10.87 years (undiscounted 14.66 years). In addition, the patients undergoing bariatric surgery would experience a better quality of life as measured by standardized quality of life questionnaires. Therefore, the model estimated a significant increase in QALYs by 0.9 to 6.78 compared to 5.88 QALYs achieved by conservative medical treatment. The model projected cost savings from bariatric surgery in the areas of patient management of type 2 diabetes (screening procedures, medication), cardiovascular disease, renal complications, while additional costs were incurred by the surgery. The overall incremental cost-effectiveness was estimated to be US\$21,973 per QALY, which would generally be accepted as cost-effective. The incremental cost per life year gained was US\$29,676. It is important to note that the degree of costeffectiveness was strongly dependent on the long-term perspective and on the estimated improvement in quality of life. The highest costs in both cohorts were those associated with cardiovascular disease (CVD), which were higher for the medical-management cohort $(\$ 37,824)$ than for the bariatric surgery cohort $(\$ 34,811)$ and represented an $8 \%$ decrease in CVD-related costs. Limitations of this study were that the model was extrapolated far beyond the time frame of the prospective data collection and that instead of collecting comparative control data these were extrapolated from previous UK studies. In sensitivity 
analyses, shortening the time horizon to 5 and 10 years and excluding the negative impact of increased body mass index on the patient's quality of life had the greatest adverse impact on the ICERs (i.e. higher cost per QALY). (Ikramuddin et al. 2009)

Chang and his collaborators used a model for a representative US population (National Health and Nutrition Examination Survey III/NHANES III) and retrieved clinical and quality of life outcomes data from a meta-analysis. They gave a preference to newer data because the outcomes of bariatric surgery have greatly improved over the last 20 years. (Chang, Stoll, and Colditz 2011) Bariatric surgery was cost-effective for obese people with BMI greater than $35 \mathrm{~kg} / \mathrm{m}^{2}$, with a cost per incremental QALY of less than US\$4,000. It was also cost-saving for patients with a BMI greater than $50 \mathrm{~kg} / \mathrm{m}^{2}$ with one or more obesityrelated comorbidity before surgery. Even for patients with a BMI above $30 \mathrm{~kg} / \mathrm{m}^{2}$, the cost per incremental QALY was only US\$4,222 for patients without comorbidities or US\$2,926 if they had comorbidities. If the willingness-to-pay-threshold is assumed to be US\$40-60,000 per QALY the results of this analysis support a broader use of bariatric surgery.

In all studies, bariatric surgery remained cost-effective in the eligible patient group. Differences could be seen among subgroups.

\subsubsection{BMI level}

Craig et al. showed decreasing cost per QALY with increasing BMI. (Craig and Tseng 2002) That means that the more obese patients are the more value they can get from the surgery. This is probably connected to the risk of comorbidities increasing with higher BMI. Similarly, Chang et al used a model to analyze the cost-utility ratio in different BMI groups. (Chang, Stoll, and Colditz 2011) While the surgery intervention was cost-effective for all levels of BMI above $35 \mathrm{~kg} / \mathrm{m}^{2}$, the cost-utility ratio decreased with increasing BMI (over $35 \mathrm{~kg} / \mathrm{m}^{2}$, over $40 \mathrm{~kg} / \mathrm{m}^{2}$, over $50 \mathrm{~kg} / \mathrm{m}^{2}$ ).

\subsubsection{Gender}

Salem et al. published an analysis of lifetime cost and incremental cost-utility for men and women from two laparoscopic bariatric surgery techniques as compared to conventional therapy. The incremental cost-utility for men aged 35 and a BMI of 40 or over was US\$11,604 per incremental QALY for laparoscopic adjustable gastric banding (LAGB) while for women it was US\$8,878. For Roux-en-Y gastric bypass (RYGB) the cost per incremental QALY was US\$18,543 for men and US\$14,680/QALY for women. (Salem et al. 2008)

\subsubsection{Cost-effectiveness for obese patients with BMI over $\mathbf{3 5}$ and type $\mathbf{2}$ diabetes}

As already mentioned in the previous discussion, a large proportion of the potential savings induced by bariatric surgery is due to the reduction in comorbidities. The reduction of medical needs and degree of remission in type 2 diabetes from bariatric surgery is best supported by data. It is, therefore, no surprise that the favourable cost-effectiveness of bariatric surgery becomes most apparent for morbidly obese patients with type 2 diabetes.

In a study conducted in Italy, Austria and Spain, a cost-effectiveness and budget impact model was used to estimate the resource utilization and cost of adjustable gastric banding and gastric bypass vs. conventional treatment in patients with a BMI $\geq 35 \mathrm{~kg} / \mathrm{m}^{2}$ and type 2 
diabetes. (Anselmino et al. 2009) In all scenarios analyzed for Italy and Austria, over a time span of 5 years, both procedures turned out to be cost-saving versus conventional treatment. In Spain there was incremental overall cost associated with both surgical interventions when compared to conventional treatment, but remained cost-effective even in the worst case scenario. Ackroyd et al. showed savings in addition to improved outcomes (QALYs) from bariatric surgery in German and French patients with type 2 diabetes. (Ackroyd et al. 2006)

An American group used the Center of Disease Control (CDC)-RTI Diabetes CostEffectiveness Markov Simulation Model to estimate the overall cost of gastric bypass or gastric banding surgery relative to conventional therapy throughout disease progression (from diagnosis of type 2 diabetes to either death or age 95 years). (Hoerger et al. 2010) The model also simulated diabetes-related complications on three microvascular disease paths (nephropathy, neuropathy, and retinopathy) and two macrovascular disease paths (coronary heart disease and stroke) and of remission and relapse of type 2 diabetes. Both surgical alternatives remained cost-effective in all scenarios but did not achieve cost-saving in this US based model. Gastric bypass surgery resulted in US $\$ 7,000 /$ QALY for patients with BMI > 35 and newly diagnosed type 2 diabetes and US\$12,000/QALY for those with diabetes existing for a longer time. Similarly, gastric banding surgery resulted in US\$11,000/QALY and US\$13,000/QALY for the respective groups. With this costeffectiveness range, both surgical alternatives remained below the typical cost-effectiveness of current anti-diabetic medications. (Hoerger et al. 2010) As an example, intensive glycemic and lipid control in comparison to conventional risk factor control have been shown to have incremental cost effectiveness ratio of US\$41,384/QALY for patients with BMI > 35 and newly diagnosed diabetes and US\$51,889/QALY for those with diabetes existing for a longer time. (CDC Diabetes Cost Effectiveness Group 2002)

A study was conducted in seven Blue Cross/Blue Shield health care plans. It was a retrospective time-series study of patients who had undergone bariatric surgery and had evidence of preoperative diabetes based on medication use. The authors concluded that bariatric surgery was associated with a reduction of $98 \%$ in the total use of medication and in a reduction of overall health care costs in patients with type 2 diabetes. They, therefore, recommended that health insurers should cover bariatric surgery because of its health and cost benefits. (Makary et al. 2010)

Another retrospective US database analysis by Klein and collaborators compared the economic impact between two matched cohorts of obese patients (BMI > 35) with type 2 diabetes with or without bariatric surgery. In this database all types of bariatric surgery before 2004 were recorded under the same code. (Klein et al. 2011) Between 2004 and 2007, $65 \%$ of the procedures were performed as laparoscopic interventions, and by 2007 they reached $94 \%$ of all bariatric surgeries. Approximately half of these were gastric banding procedures. The authors found that in the latter years, on average it took 29 months (range 21-38) to fully recoup the cost of open surgery (US\$ 28,845) and 26 months (range 20-32) for the cost of laparoscopic procedures (US\$ 19,124). While in the no surgery control group, the rate of diabetes diagnosis or prescription claims fell to approximately $80 \%$, it dropped to around $25 \%$ in the surgery group. In addition, medication supply cost slightly increased in the control group and it dropped by $80 \%$ in the surgery group, and remained stable throughout 36 months after surgery. (Klein et al. 2011) 
Because of the strong clinical evidence the International Diabetes Federation (IDF) in 2011 officially published a consensus statement supporting the positive impact of bariatric surgery on clinical and economic diabetes related outcomes. Consequently, IDF called for National guidelines for bariatric surgery in patients with type 2 diabetes and a BMI of $35 \mathrm{~kg}$ $/ \mathrm{m}^{2}$ or more to be developed and promoted. (J B Dixon et al. 2011)

In a recent discussion of existing evidence, Villamizar suggested that due to both the positive clinical and economic impact to extend the eligibility criteria for bariatric surgery in the diabetic population even further to include patients a BMI of $30 \mathrm{~kg} / \mathrm{m}^{2}$ or above. (Villamizar and Pryor 2011) Health plans and other budget holders would have to expect increased short term cost, with a negative impact on their short term financial resources, and savings would only be expected two to three years after surgery. This may be one reason why payer organizations hesitate to give better access to bariatric surgery for all patients eligible per guideline definitions.

\subsection{Comparison of types of surgery}

After conservative weight reduction attempts failed and a decision to perform bariatric surgery has been made, there are different methodological approaches to bariatric surgery, which have been presented and discussed in other chapters of this book. Each intervention has advantages or disadvantages for specific patient groups. The three currently most used methods are gastric bypass surgery ${ }^{2}$, adjustable gastric banding 3 , and sleeve gastrectomy 4 . The individual patient profile (e.g. eating habits, BMI, general health, readiness to assume risk, eagerness for fast results) should be considered when making the decision for the most suitable surgical type. From the patient's perspective, the surgery center's capabilities and historical success rates in the specific type of surgery are important factors to consider.

There is sufficient evidence to support offering a choice of procedures and making the decision together with the patient. The choice depends on his or her risk profile, eating habits, BMI, psychosocial situation, and personal preferences (Table 2 and Fig. 1). When performed in a surgical center experienced in obesity care, bariatric surgery usually achieves the goals of obesity therapy with acceptable low risk of surgery-related complications. In addition, Encinosa et al. were able to show in a retrospective insurance claims data analysis in the USA that the use of laparoscopy reduced total healthcare costs by $12 \%$, while gastric banding decreased costs by $20 \%$. Laparoscopy had no impact on readmissions; the increase in banding without bypass reduced readmissions. (Encinosa 2009).

In the USA, laparoscopic gastric bypass and laparoscopic gastric banding are currently the two most commonly performed operations for the treatment of morbid obesity, (Hinojosa et al. 2009) although sleeve gastrectomy is increasingly used as an effective method of bariatric

\footnotetext{
${ }^{2}$ Gastric bypass surgery involves the creation of a small gastric pouch and a shortcut of the remaining stomach and parts of the GI tract (bypass)

${ }^{3} \mathrm{~A}$ band placed around the upper part of the stomach to create a small pouch limits the amount of food intake at a time and can be adjusted regularly to maintain the effectiveness.

4 The stomach is reduced to about $25 \%$ of its original size, by surgical removal of a large portion of the stomach, following the major curve. The open edges are then attached together to form a sleeve or tube. The procedure permanently reduces the size of the stomach.
} 
surgery. Many cost-utility studies which evaluated various types of surgery methods in different patient groups have been published and are summarized in Table 2.

Nguyen et al. conducted a randomized controlled trial comparing gastric bypass and gastric banding with respect to short and long term clinical outcomes, cost, and quality of life impact with 111 patients undergoing gastric bypass surgery and 86 patients receiving gastric banding surgery. (Nguyen et al. 2009) The study showed that a higher complexity of gastric bypass surgery is reflected in a longer time needed for surgery and recovery (see Table 3). Increasing complexity was also associated with higher complication rates and higher total cost. On the other hand, gastric bypass surgery was more effective for weight loss in terms of the extent of weight loss and the response rate. The authors suggested considering the trade-offs of increased complexity, cost, and complications versus improved weight outcomes, when making the decision on which type of surgery is the best for the individual patient. They also argued that even the inferior weight loss after the gastric banding procedure is far better than any non-surgical intervention and led to the same improvement of quality of life for the patients as gastric bypass surgery.

\section{Conservative Options}

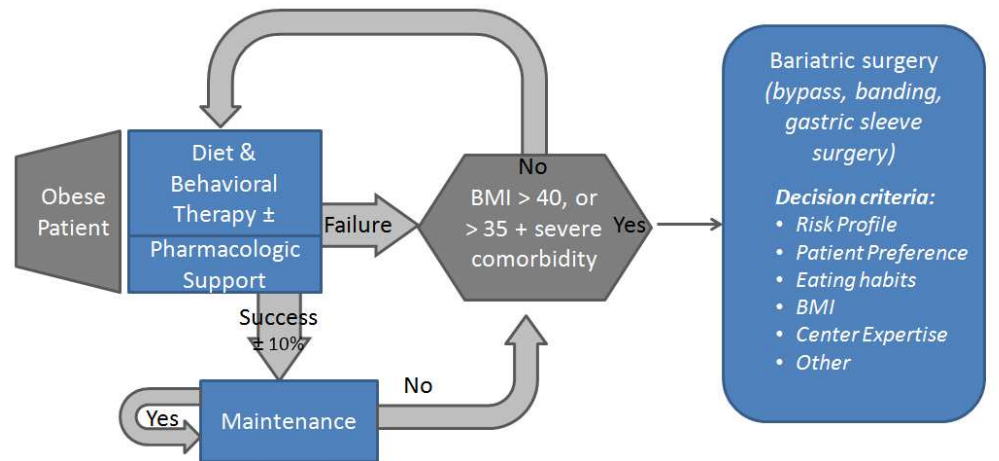

Fig. 1. Conceptual treatment path of obese patients

A smaller study was conducted by Ojo et al. in a hospital in New Haven, CT / USA and compared the cost of 83 laparoscopic adjustable gastric banding (LAGB) procedures with the cost of 59 laparoscopic vertical banded gastroplasty (LVBG) procedures. (Ojo and Valin 2009) This group found in their setting a cost advantage for LVBG (US\$1,927 lower cost of surgery but a somewhat higher follow-up cost). The authors found however, that the excess weight loss in LVBG patients was realized more rapidly than in LAGB patients.

Another research group in the USA (Campbell et al. 2010) used the results of a five year European randomized clinical trial published in 2007 (Angrisani, Lorenzo, and Borrelli 2007) and base data from a systematic review of 36 English-language studies of weight loss outcomes following LAGB or laparoscopic RYGB (O'Brien et al. 2006). The authors conclusion was that both LAGB and LRYGB provided significant weight loss and were costeffective compared to conventional treatment at accepted thresholds for medical interventions. (Campbell et al. 2010) In the base case of the overall eligible population the incremental cost per life year saved was US $\$ 9,300$ for LAGB and US $\$ 10,200$ for LRYGB versus conventional therapy. The cost-utility was US\$5,400 for LAGB and US\$5,600 for 
LRYGB versus conventional therapy. Comparing the two methods, LRYGB had an ICER of US\$12,900 / Life Year saved versus LAGB and an ICUR of US\$6,200 per QALY. The cost utility ratio improved with increasing morbidity and was generally better for females. However, in all cases the ICUR remained below US\$15,000/QALY and the surgical procedures both were cost saving and improved clinical outcomes for females with a BMI > $50 \mathrm{~kg} / \mathrm{m}^{2}$. (Campbell et al. 2010) Since the input data originated from data collected before 2006, it can be assumed that the rate of surgery related mortality and complications were overestimated in this model compared to today. Therefore the cost-effectiveness would be expected to be even more favourable for both types of surgery.

Table 2 summarizes studies that reported on cost-utility analyses of bariatric surgery.

\begin{tabular}{|c|c|c|c|c|c|}
\hline & $\begin{array}{l}\text { Data } \\
\text { Year }\end{array}$ & $\begin{array}{l}\text { Cost/ } \\
\text { QALY }\end{array}$ & $\begin{array}{l}\text { Method/ } \\
\text { Country }\end{array}$ & Patient Type & Limitations \\
\hline $\begin{array}{l}\text { Craig, Tseng } \\
2002\end{array}$ & $\begin{array}{l}1997- \\
2001\end{array}$ & $\begin{array}{c}\$ 28,600 \\
\$ 10,700 \\
\$ 14,700 \\
\$ 5,700 \\
\$ 35,600 \\
\$ 13,300 \\
\$ 16,100 \\
\$ 5,400\end{array}$ & GB /USA & $\begin{array}{l}\text { M. BMI > 40, A } 35 \\
\text { M, BMI > 50, A } 35 \\
\text { W, BMI > 40, A } 35 \\
\text { W, BMI > 50, A } 35 \\
\text { M. BMI > 40, A } 50 \\
\text { M, BMI > 50, A } 50 \\
\text { W, BMI > 40, A } 50 \\
W, \text { BMI > 50, A } 50\end{array}$ & $\begin{array}{l}\text { Cost for treatment for many obesity-related } \\
\text { diseases (such as gastro-esophageal reflux } \\
\text { disease, sleep apnea, and degenerative joint } \\
\text { disease) were not included }\end{array}$ \\
\hline $\begin{array}{l}\text { Clegg et al. } \\
2003\end{array}$ & $<2002$ & $\begin{array}{c}£ 6,289 \\
£ 8,527 \\
£ 10,237\end{array}$ & $\begin{array}{c}\text { GB/UK } \\
\text { AGB/UK } \\
\text { VBG/UK }\end{array}$ & & $\begin{array}{l}\text { Cost estimates after one year only based on } \\
\text { expert opinion. Only diabetes as cost of } \\
\text { comorbidity; no productivity considerations. }\end{array}$ \\
\hline $\begin{array}{l}\text { Ackroyd et } \\
\text { al. } 2006\end{array}$ & $<2005$ & $\begin{array}{c}£ 3,251 \\
£ 2,599 \\
€(1,305) \\
€(2,208) \\
€(1,379) \\
€(4,000)\end{array}$ & $\begin{array}{c}\text { AGB/UK } \\
\text { GB/UK } \\
\text { AGB/GER } \\
\text { GB/GER } \\
\text { AGB/FRA } \\
\text { GB/FRA } \\
\end{array}$ & $\begin{array}{l}\text { Patients with } \\
\text { T2DM }\end{array}$ & $\begin{array}{l}\text { Payor perspective. No productivity data. 5- } \\
\text { year time frame. Limited sensitivity analysis } \\
\text { i.e. testing of extreme points }\end{array}$ \\
\hline $\begin{array}{l}\text { Salem et al. } \\
2008^{*}\end{array}$ & 2004 & $\begin{array}{c}\$ 11,604 \\
\$ 18,543 \\
\$ 8,878 \\
\$ 14,680\end{array}$ & $\begin{array}{l}\text { LAGB/USA } \\
\text { RYGB/USA } \\
\text { LAGB/USA } \\
\text { RYGB/USA }\end{array}$ & $\begin{array}{l}\text { M. A 35; BMI } 40 \\
\text { W. A 35; BMI } 40\end{array}$ & $\begin{array}{l}\text { Incremental cost effectiveness ratio (ICER) } \\
\text { of LAGB or LRYGB as compared with } \\
\text { medical interventions }\end{array}$ \\
\hline $\begin{array}{l}\text { Ikramuddin } \\
\text { et al. } 2009\end{array}$ & $\begin{array}{c}2001- \\
2007\end{array}$ & $\begin{array}{l}\$ 21,973 \\
\$ 122,001\end{array}$ & GB/USA & $\begin{array}{l}35 \text { year time horizon } \\
10 \text { year time horizon }\end{array}$ & $\begin{array}{l}\text { CORE Diabetes Model for T2DM or pre- } \\
\text { diabetes. Comparison GB surgery versus } \\
\text { Medical Treatment. }\end{array}$ \\
\hline $\begin{array}{l}\text { Campbell et } \\
\text { al. } 2010\end{array}$ & $<2006$ & $\begin{array}{l}\$ 5,400 \\
\$ 5,600\end{array}$ & $\begin{array}{c}\text { LAGB/USA } \\
\text { LRYGB }\end{array}$ & & $\begin{array}{l}\text { Input data from previous European or } \\
\text { literature review }\end{array}$ \\
\hline $\begin{array}{l}\text { Chang et al. } \\
2011\end{array}$ & $\begin{array}{l}2010 \\
\text { price } \\
\text { levels }\end{array}$ & $\begin{array}{c}\$ 2,413 \\
\$ 3,872 \\
\$ 1,853 \\
\$ 3,770 \\
\text { dominant } \\
\$ 1,904 \\
\end{array}$ & all types & $\begin{array}{l}\mathrm{BMI}>35<40, \text { ORD } \\
\mathrm{BMI}>35<40, \text { no ORD } \\
\mathrm{BMI}>40<50, \text { ORD } \\
\mathrm{BMI}>40<50, \text { no ORD } \\
\mathrm{BMI}>50, \text { ORD } \\
\mathrm{BMI}>50, \text { no ORD }\end{array}$ & $\begin{array}{l}\text { Model for a population (age } \geq 17 \text { ), obtained } \\
\text { from National Health and Nutrition } \\
\text { Examination Survey (NHANES) III and data } \\
\text { from meta-Analysis including RCT and non- } \\
\text { RCT data }\end{array}$ \\
\hline $\begin{array}{l}\text { Hoerger et } \\
\text { al. } 2010\end{array}$ & $\begin{array}{l}2005 \\
\text { price } \\
\text { levels }\end{array}$ & $\begin{array}{l}\$ 7,000 \\
\$ 1,000 \\
\$ 12,000 \\
\$ 13,000\end{array}$ & $\begin{array}{l}\text { GB/USA } \\
\text { AGB/USA }\end{array}$ & $\begin{array}{l}\text { Newly diag. T2DM } \\
\text { Established T2DM } \\
\text { Newly diag. T2DM } \\
\text { Established T2DM }\end{array}$ & $\begin{array}{l}\text { Centers for Disease Control and Prevention- } \\
\text { RTI Diabetes Cost-Effectiveness Model } \\
\text { extended to bariatric surgery }\end{array}$ \\
\hline
\end{tabular}

Table 2. List of studies reporting cost-utility ratios (Cost/QALY). M=Men; W=Women; $\mathrm{ORD}=$ Obesity Related Disease 


\begin{tabular}{|c|c|c|c|}
\hline & $\begin{array}{c}\text { Gastric Bypass } \\
\qquad \mathbf{N}=\mathbf{1 1 1}\end{array}$ & $\begin{array}{c}\text { Gastric } \\
\text { Banding } \\
\mathrm{N}=86\end{array}$ & $\mathbf{P}$ \\
\hline \multicolumn{4}{|l|}{ Peri-surgery outcome } \\
\hline Operative time (minutes) & $136.9 \pm 31.9$ & $68.21 \pm 24.7$ & $<0.01$ \\
\hline Estimated blood loss & $4 x$ & Reference (1) & $<0.01$ \\
\hline Length of hospital stay & $3.1 \pm 1.5$ & $1.5 \pm 1.1$ & $<0.01$ \\
\hline ICU use & $2.7 \%$ & $1.2 \%$ & N.S. \\
\hline 30 day mortality & 0 & 0 & N.S. \\
\hline \multicolumn{4}{|l|}{ Recovery } \\
\hline Return to daily living activities (d) & $14.5 \pm 12.7$ & $10.4 \pm 10.1$ & $<0.02$ \\
\hline Return to work $(\mathrm{d})$ & $21.0 \pm 13.65$ & $14.0 \pm 10.1$ & $<0.01$ \\
\hline \multicolumn{4}{|l|}{ Complications } \\
\hline Major early complications & $6.3 \%$ & $2.3 \%$ & N.S. \\
\hline Minor early complications & $15.3 \%$ & $4.7 \%$ & 0.02 \\
\hline Major late complications & $26.1 \%$ & $11.6 \%$ & 0.01 \\
\hline Minor late complications & $13.5 \%$ & $0 \%$ & $<0.01$ \\
\hline 30 day reoperation & $5.4 \%$ & $1.2 \%$ & N.S. \\
\hline Late reoperation & $7.2 \%$ & $11.6 \%$ & N.S. \\
\hline 90 day mortality & 0 & 0 & N.S. \\
\hline \multicolumn{4}{|l|}{ Weight Loss } \\
\hline Excess weight loss 2 yrs & $68.9 \%$ & $41.8 \%$ & \\
\hline Excess weight loss 4 yrs & $68.4 \%$ & $45.4 \%$ & \\
\hline \multicolumn{4}{|l|}{ Treatment success and failure rate } \\
\hline $\begin{array}{l}\text { Treatment failure rate (excl. patients lost to } \\
\text { follow-up) }\end{array}$ & $0 \%$ & $16.7 \%$ & \\
\hline $\begin{array}{l}\text { Treatment failure rate (incl. patients lost to } \\
\text { follow-up) }\end{array}$ & $15.3 \%$ & $23.3 \%$ & \\
\hline $\begin{array}{l}\% \text { age of patients with adequate or good weight } \\
\text { loss }\end{array}$ & $35.9 \%$ & $67.9 \%$ & \\
\hline $\begin{array}{l}\% \text { age of patients with excellent or exceptional } \\
\text { weight loss }\end{array}$ & $54.1 \%$ & $15.3 \%$ & \\
\hline \multicolumn{4}{|l|}{ Total Cost } \\
\hline Total cost (US\$) & $12,310 \pm 3,099$ & $10,767 \pm 1,631$ & $<0.01$ \\
\hline \multicolumn{4}{|l|}{ Quality of Life (SF 36) } \\
\hline QoL after 1 month & $\begin{array}{l}\text { Improved in } 5 \\
\text { of } 8 \text { domains }\end{array}$ & $\begin{array}{l}\text { Improved in } 1 \\
\text { of } 8 \text { domains }\end{array}$ & \\
\hline QoL after 1 year & $\begin{array}{l}\text { Improved to } \\
\text { normal in all } \\
\text { domains }\end{array}$ & $\begin{array}{l}\text { Improved to } \\
\text { normal in all } \\
\text { domains }\end{array}$ & \\
\hline
\end{tabular}

Table 3. Summary of study results of randomized controlled trial comparing laparoscopic gastric bypass surgery and laparoscopic gastric banding for clinical, economic, and quality of life outcomes 
The evidence shows that both LAGB and RYGB are cost-effective. However, there is no clear evidence supporting superior cost-effectiveness of either surgical intervention compared to the other but there is a tendency that with increasing proficiency and experience LAGB may decrease cost by (1) requiring shorter time for surgery, hospitalization and recovery (2) lowering peri-surgical morbidity and mortality and (3) reducing severe surgery-related morbidity in the short and long term.

\subsection{Budget impact, break-even or time to payback}

A study by Cremieux et al., using a private insurer claims database, quantified the effect of bariatric surgery on direct medical costs in 3,651 US patients for up to five years after bariatric surgery. (Cremieux et al. 2008) Compared to a matched group of morbidly obese patients with similar comorbidity profile, but did not receive bariatric surgery, the authors found that the surgery group accrued incremental costs of approximately US\$24,500 for all types of bariatric surgery combined (US\$26,000 for open surgery, and US $\$ 17,000$ for laparoscopic surgery) during the period from one month before surgery to two months following surgery. From month three onwards, cost savings associated with the bariatric surgery patients started accumulating. One and a half years after surgery the monthly savings associated with bariatric surgery reached more than US\$500 for the whole sample. Monthly savings associated with laparoscopic bariatric surgery reached more than US\$900 as early as 13 months following surgery $(\mathrm{P}<0.01)$. Open surgery between 2003 and 2005 achieved the break-even after 49 months ( $95 \% \mathrm{CI},-35$ to 63 months), and the cost of laparoscopic surgery were fully recovered after 25 months (95\% CI, -16 to 34 months). The savings came from reductions in prescription drug costs, physician visit costs and hospital costs (including emergency department visits and inpatient and outpatient visits). The reduced cost was associated with multiple major diagnosis categories, including type 2 diabetes, coronary artery disease, hypertension, and sleep apnea. This analysis had several conclusions:

- The cost of laparoscopic bariatric surgery could be recovered after a little over two years. The savings accrued came mainly from reduced use of medication and healthcare services originating from comorbidities.

- Laparoscopic interventions were more cost-effective than the open surgery alternatives.

- Outcomes from surgery improved over time as the surgical team gained more experience, especially during the first few years. When analyzing the accumulated cost in the surgery group before 2003, an average of 77 months was needed to recover the investment (95\% CI, -48 to 106 months).

- Third-party payers should invest in bariatric surgery because it generally will pay for itself through decreased comorbidities within two to four years in addition to potential quality-of-life and length-of-life benefits, as well as reduction in disability and work loss.

To confirm the observation of effective reduction of comorbidities, Cremieux et al. conducted another study where they analyzed data from 5,502 patients in the same database for comorbidity related claims before and after surgery. (Cremieux et al. 2008) Compared to the period before surgery, significant decreases $(p<0.05)$ were observed as early as 120 days after surgery and remained lower until three years after surgery. All cardiovascular disorders decreased from $43.6 \%$ pre-surgery to $14.2 \%$ post-surgery. The diagnosis of diabetes mellitus fell from $19.9 \%$ to $7.7 \%$. Chronic obstructive pulmonary disease and other respiratory conditions also improved by over 40 percentage points (from $57.7 \%$ before to 
$16.2 \%$ after surgery). In addition, prevalence of diseases of the musculoskeletal system and connective tissue was reduced from $32.6 \%$ to $27.7 \%$, and mental disorders were approximately halved with $30.7 \%$ before and $14.8 \%$ after surgery.

Simultaneously, the medication use dropped significantly for a number of conditions including infections, pain, respiratory disease, cardiovascular disease, gastroenterological diseases, and diabetes. In addition, there was an improvement in the lipid profile of the patients. Anemia, however, increased from 3.8\% to $9.9 \%$ and use of nutritional supplements increased significantly. Both are known consequences of the surgery.

A similar analysis of claims data (US MarketScan Commercial Claims and Encounters Database from January 1, 2003 to March 31, 2008) of more than 7,000 patients having undergone laparoscopic adjustable gastric banding surgery was published in 2011. (Finkelstein et al. (a) 2011) They determined that the average cost of surgery was approximately US\$20,000 and that this investment was recouped within two years for the diabetic population and within four years for the non-diabetic patient group due to decreased utilization of healthcare services and medication.

A subsequent study used data from the US Medical Expenditure Panel Survey (MEPS) and data from the US National Health and Wellness Survey (NHWS) to calculate the time needed to recoup the cost of bariatric surgery when including direct medical cost (hospital, drugs, clinical services, etc.) and indirect cost (absenteeism and presenteeism) of obese patients who were eligible for bariatric surgery. (Finkelstein et al. (b) 2011) They concluded that it takes nine quarters to recoup the cost of surgery. The improvement in absenteeism or presenteeism balanced the time of lost work when the patients underwent the surgery. Beyond the break-even time horizon there are additional indirect benefits that accrue to employers as a result of the procedure.

Perry et al. analyzed 11,903 surgery patients matched to 11,901 controls selected from 190,448 Medicare patients matched for age, sex and comorbidity in the USA. (Perry et al. 2008) Throughout two years, the incidence of several obesity related diseases were reduced when compared to the control group (all results were statistically highly significant):

- $\quad$ Diabetes fell by $21 \%$

- $\quad$ Sleep apnoea by $10 \%$

- Hypertension by $21 \%$

- Hyperlipidemia by $30 \%$

- Coronary artery disease by $32 \%$.

In contrast to the above studies, an analysis of long-term health care utilization and expenditures among veterans in the USA that underwent bariatric surgery in 12 Veteran Affairs (VA) medical centers from 2000 to 2006 did not reveal a reduction in overall health expenditures by the end of three years. The data indicated a significant decrease in outpatient health expenditures, but this reduction was offset by a significant increase in inpatient health expenditures. (Maciejewski et al. 2010) Several factors may have contributed to this result, including the fact that the analysis targeted a special subset of patients usually older than average patients undergoing bariatric surgery, had a higher degree of long established comorbidities and were male. In addition, none of the patients received laparoscopic banding procedures and only a minority of the surgeries used laparoscopic or less invasive methods. 
More studies and models have attempted to calculate the time to break-even, or the time needed until an intervention starts to generate more savings than it cost.

Table 4 lists the results from several studies and, depending on the point of view, these authors expected the break-even in one to ten years. It depends on the type of cost and the comparators considered when the break-even point is reached - or even if it is reached. Employers paying for the healthcare of their employees would be interested in improved productivity and reduced absenteeism. From their point of view productivity and absenteeism should be included in the beak-even or time to pay-back calculations. On the other hand, insurers or national health systems might only be interested in the direct medical cost.

\begin{tabular}{|c|c|c|}
\hline Publikacation & Country & Break-even or time to pay-back \\
\hline Finkelstein; Brown 2005 & USA & $5-10$ years for employer to recover cost \\
\hline Snow et al. 2004 & USA & Break-even after 2-3 years \\
\hline Narbro et al. 2002 & Sweden & Total cost similar \\
\hline Christou et al. 2004 & Canada & $2-3$ years \\
\hline Sampalis et al. 2004 & Canada & 2-3 years \\
\hline Gallagher et al. 2003 & USA & $\begin{array}{l}\text { Cost is off set in year } 1 \text { through reduction of } \\
\text { outpatient visits in Veteran's Affairs population }\end{array}$ \\
\hline Maciejewski et al. 2010 & USA & No break-even in Veteran's Affairs population \\
\hline Mullen; Marr 2010 & USA & 3.5 years after gastric baypass \\
\hline Cremieux et al. 2008 & USA & $\begin{array}{l}53 \text { months for bariatric surgery overall } \\
25 \text { months for laparoscopic bariatric surgery }\end{array}$ \\
\hline Finkelstein et al. 2011(a) & USA & $\begin{array}{l}2 \text { years for diabetic patients } \\
4 \text { years for non-diabetic patients }\end{array}$ \\
\hline Finkelstein et al. 2011(b) & USA & $\begin{array}{l}2.25 \text { years for all patients, including direct and } \\
\text { indirect cost \& savings }\end{array}$ \\
\hline
\end{tabular}

Table 4. Summary of studies, which report a 'break-even' time for bariatric surgery cost

Several studies find that LAGB and RYGB are cost saving and improve clinical outcomes when compared to conventional therapy. Both procedures also have a relatively short time before reaching break-even (two to 10 years). (Cremieux et al. 2008)

\subsection{Geographic areas}

Most of the evidence on economic impact of bariatric surgery has been generated in the United States and in Europe. Several European countries as well as Canadian authorities and some US payer organizations have assessed the technology systematically by looking at the clinical and the economic evidence. The conclusions were not always consistent and depended on the evidence reviewed, the perspective of the evaluation, and the time frame assessed. Therefore, many assessments remain indecisive in their final conclusion and requested further evidence to be generated. 


\subsubsection{Europe}

The recent health technology assessment in the UK, performed in 2009, included a literature review of the key published clinical studies and cost-effectiveness analysis. In addition, the cost-effectiveness of bariatric surgery was further analyzed in two models. (Picot et al. 2009) The incremental cost-effectiveness ratios (ICERs) ranged between $£ 2,000$ and $£ 4,000$ per QALY gained. The results were generally robust to changes in assumptions in the sensitivity analysis, and in all cases the ICERs remained within the range conventionally regarded as cost-effective from an NHS decision-making perspective. Surgical management (with AGB) of moderate to severe obesity (BMI $\geq 30$ and $<40$ ) in patients with type 2 diabetes was more costly than nonsurgical management, but resulted in improved clinical outcomes. The ICER was reduced with a longer time horizon, from $£ 18,930$ at two years to $£ 1,367$ at 20 years. The authors also analyzed the cost effectiveness of the intervention for the patients with a BMI between 30 and 35. Based on data from two clinical trials, the QALY gain at two years was small (0.08). The ICER was again reduced with a longer time horizon, from $£ 60,754$ at two years to $£ 12,763$ at 20 years. (Picot et al. 2009) The general conclusion was that bariatric surgery was a clinically effective and cost-effective intervention for moderately to severely obese people compared with non-surgical interventions.

The UK National Institute for Health and Clinical Excellence (NICE) guidelines state that bariatric surgery should be offered to patients with a BMI of 35 - 40 who have other conditions caused by being overweight, such as diabetes and obstructive sleep apnea or hypertension and all appropriate non-surgical measures have been tried but have failed to achieve or maintain adequate, clinically beneficial weight loss for at least 6 months or for those with a BMI of 40-50 with no other weight related conditions. For those with a BMI of 50 and over bariatric surgery can be offered as a first-line treatment (NICE Guideline CG43, 2010).

A health technology assessment conducted by a German expert group came to the conclusion that bariatric surgery seemed to be clinically effective and cost-effective, based on an extensive literature analysis. (Bockelbrink et al. 2008) At this time, no specific German cost-effectiveness analysis has been conducted.

Finland's health technology assessment agency (FINOHTA) included a cost-utility analysis for the most commonly used surgical techniques from the healthcare provider perspective over a ten year time frame. They concluded that bariatric surgery in Finland was more effective and less costly than the conventional therapy for morbid obesity and was the dominant technology. (Mäklin et al. 2009)

\subsubsection{Canada}

A recent health technology assessment from the Canadian authorities concluded that over a time period of 20 years, bariatric surgery for morbidly obese patients appeared to be costeffective with an ICER of US\$5,000 to US\$30,000 / QALY. (Padwal et al. 2011; Klarenbach et al. 2010) For patients with type 2 diabetes, the intervention was recognized as cost saving and with improved outcomes. A retrospective data analysis performed in Quebec found cost savings after 3.5 years from bariatric surgery due to reduced health care utilization for a variety of obesity related disorders. (Sampalis et al. 2004) A new analysis is currently ongoing, where three patient groups are compared for clinical, quality of life, and cost outcomes for one year retrospectively and two years prospectively after referral or surgery. 
The study will include 150 surgical cases, 200 medically treated controls, and 150 wait-listed controls. (APPLES study; (Padwal et al. 2010)). Final results for the APPLES analysis are anticipated by late 2012 or early 2013.

\subsubsection{Australia}

Keating and colleagues compared the cost to achieve diabetic remission in 60 morbidly obese patients through LAGB or conventional treatment in a two year randomized clinical trial in Australia. (Keating et al. 2009a) The study showed that in the time frame of the two-year study period, AU\$16,000 additional expenditure for the surgical intervention was needed per additional remission of diabetes. The highest cost difference was detected in the first six months of the study period including the cost of the surgery and the short-term complications. Savings were subsequently demonstrated for the surgery group in the consumption of antidiabetic medicine, with increasing consumption by the patients without bariatric surgery.

Subsequently, the same group of researchers extended the study results into an incremental cost-effectiveness Markov model and extrapolated the intervention costs based on the observed resource utilization during the trial. (Keating et al. 2009b) In this lifetime model, the mean discounted cost per patient was AU $\$ 98,900$ for surgical therapy and AU $\$ 101,400$ for conventional therapy. Over a lifetime, the health-care cost to treat type 2 diabetes became the overwhelming cost driver and cost differential between the two intervention groups. The researchers found a $57 \%$ chance of surgery to be cost saving, a $98 \%$ chance to be very cost-effective (below AU $\$ 7,000 / Q A L Y$ ) and even in the worst-case scenario, surgery remained cost-effective with AU\$39,700/QALY. The authors concluded that based on this trial in the Australian setting the cost of bariatric surgery (LAGB) for patients with BMI > 35 and type 2 diabetes should be recovered within 10 years after surgery.

\subsubsection{Latin America}

There is limited literature available for the use and cost-effectiveness of bariatric surgery in Latin America. One publication by Salgado et al. calculated the actual cost of bariatric surgery in the hospital setting and contrasted it with the very low standard reimbursed rate by the public health insurance ( $R 3,260$ in 2004; $R \$ 4,615$ after August 2007). (Salgado Júnior et al. 2010) The calculation was only based on 9 patients treated in 2004 (average cost of $\mathrm{R} \$ 6,845$ /surgery) and 7 patients treated in 2007 (average cost of $\mathrm{R} \$ 7,525 /$ surgery) and no outcomes or cost-effectiveness were reported.

\subsection{Effect on productivity (paid work)}

Obesity tends to lead to reduced income. (Flum et al. 2005; Martin et al. 2010) It was estimated in New Mexico that the total labor income impact of obesity was nearly US\$200 million, representing US $\$ 1,660$ of output income and US $\$ 245$ of labor income per household. Obesity may cost New Mexico more than 7,300 jobs and cuts state and local tax revenues by more than US\$48 million. (Frezza and Wachtel 2009)

Few studies have examined the impact of bariatric surgery on productivity. According to a US analysis, obese workers eligible for bariatric surgery have $5.1(\mathrm{P}<0.01)$ additional days of absenteeism and US\$2,230 (in 2004 dollars) ( $<<0.01$ ) higher annual medical costs than persons of a BMI of less than 25. (Finkelstein and Brown 2005) Given that bariatric surgery 
has been shown to increase life expectancy and to reduce the impact of overweight and comorbidities an increase in productivity would be expected. (Frezza and Wachtel 2009)

A retrospective analysis in the Duke Health and Safety Surveillance System compared data of morbidly obese workers (BMI $\geq 40$ ) with workers with a BMI 18.5 to 24.9 and revealed that the obese workers generated twice the amount of claims with 6.8 times higher medical claims cost and 11 times higher indemnity claims cost. In addition they lost 12.9 times more workdays than the non-obese workers. (Ostbye et al. 2007)

A UK study followed 59 patients for 14 months after bariatric surgery. (Hawkins et al. 2007) Before the surgery $58 \%$ of the patients worked, with an average work week of 30.1 hours, and $32 \%$ claimed some sort of incapacity benefits. After surgery $76 \%$ of the patients worked, with an average work week of 35.8 hours, and only $10 \%$ claimed benefits. The work or productivity profile of the patients after bariatric surgery looked very similar to that of the average population. Taking both the increase in percentage of people that worked and the increase in average number of hours worked per week, there was a $57 \%$ total increase in number of hours worked per week.

In a Dutch study the employment level was $53 \%$ before bariatric surgery and after surgery rose to $80 \%$. (van Gemert et al. 1998) Since 1998, when the Dutch study was published, the outcome of bariatric surgery has improved significantly and it can be assumed that the impact on productivity would be even higher today.

\subsection{The cost impact of full reimbursement of bariatric surgery}

As was outlined in the beginning of this paper, payers are concerned with the potential high short-term cost as a consequence of broader access to bariatric surgery according to the clinical guidelines. There is, however, evidence that the utilization might not grow at a very high rate. In 2010, Kim et al. published their analysis of frequency of bariatric surgery in an employer insurance setting, which had decided to give free access to bariatric surgery to those who were eligible. The data showed that one year before the new policy 18 persons had a bariatric surgery with a utilization rate of $1.71 \%$. In the year after the policy change, 16 people elected surgery with a utilization rate of $1.42 \%$.(Kim, White, and Buffington 2010) The frequency of bariatric surgery in the United States may even have levelled at around 110-120,000 procedures per year despite an increasing prevalence of obesity and a prominent decrease in complication rates. (Livingston 2010) This indicates that there is a considerable barrier for patients to elect this intervention and it may not be the preferred solution for all morbidly obese patients. Fears connected to the perceived risk of the procedure and the perceived negative impact on quality of life after the intervention may be a reason for the barrier.

It may appear that the utilization of bariatric surgery will only increase slowly and the additional short term burden on payer budgets will remain a relatively controlled level. In addition, the evidence is strong that the number of bariatric surgeries might increase short term cost, but can be expected to generate mid- to long-term benefits at acceptable costs or even savings.

\section{Conclusions on the value of bariatric surgery}

Based on currently available clinical evidence, bariatric surgery is an effective method to decrease the long-term risk of obesity for morbidly obese patients. Bariatric surgery can 
effectively reduce disease sequelae of obesity such as diabetes, hypertension, sleep apnea, cancer and cardiovascular disease and reduces mortality from these diseases.

The different types of bariatric surgery have all been effective in reducing weight and diseases related to obesity. They do, however, have different levels of intervention risk as conceptualized in Fig. 2.

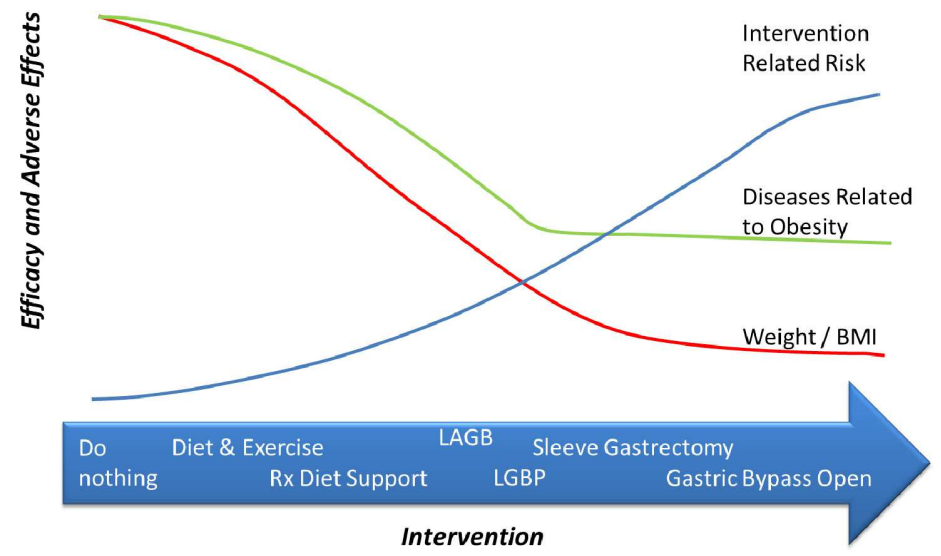

Fig. 2. Conceptual summary of clinical outcomes of treatment alternatives for morbidly obese patients. LAGB: Laparoscopic Adjustable Gastric Banding; LGBP: Laparoscopic Gastric Bypass

The investment in bariatric surgery is generally considered relatively high (US\$7,000 to US $\$ 25,000$ ) and there is reluctance to reimburse this kind of surgery. When a longer timeframe is considered, which would include reduction in cost of comorbidities, bariatric surgery for eligible obese patients is cost effective or even cost saving for many patients. For obese patients with existing obesity related comorbidities, like type 2 diabetes, bariatric surgery becomes even more cost effective and some studies have shown it to be cost saving. Evidence has also shown that the more experience the surgeons and the care team have, the more clinical outcomes are improved and bariatric surgery becomes more cost-effective. Despite the evidence supporting the cost-effectiveness or even cost savings for bariatric surgery, it seems that there are only a limited number of patients willing to elect this type of intervention. This may be due to the risk perceived by the patients and the fear of the behavioural consequences of the surgery and their impact on the subsequent lifestyle.

In conclusion: Bariatric surgery is cost-effective or cost saving for eligible patients, usually with a relatively short payback time. It can be even more cost-effective or often cost saving, for patients with obesity related comorbidities, especially when they are treated by experienced surgical and care teams. Given the positive impact on length of life and quality of life and considering the increasingly efficient and reliable methodologies and care process used today, bariatric surgery has become an attractive investment for eligible obese patients.

\section{Appendix - methods (review of health economic publications on bariatric surgery)}

The English-language literature was searched with Medline, PubMedCentral and the National Library of Medicine Catalog in 2008, 2009 and 2011. A search for relevant articles 
was conducted by entering the terms "bariatric surgery", "obesity surgery" or "morbid obesity" and "outcomes". For relevant article that were found, a "related article" search was performed. Additionally a search was based on MESH terms as listed below.

- MESH Terms:

- Gastric Bypass + Treatment Outcome

- Gastric Bypass/economics

- Gastroplasty + Treatment Outcome

- Gastroplasty /economics

- Treatment Outcome + Obesity,

- Morbid Obesity/ complications,

- Morbid Obesity + Treatment Outcome

- Obesity, Morbid

- Obesity, Morbid/complications

- Obesity, Morbid/complications

- Obesity, Morbid + Cost, Cost Analysis

- Obesity, Morbid/diet therapy

- Obesity, Morbid/drug therapy

- Obesity/economics/*surgery

- Obesity, Morbid + Health Care Cost

- Obesity, Morbid/*surgery

- Obesity, Morbid + Treatment Outcome

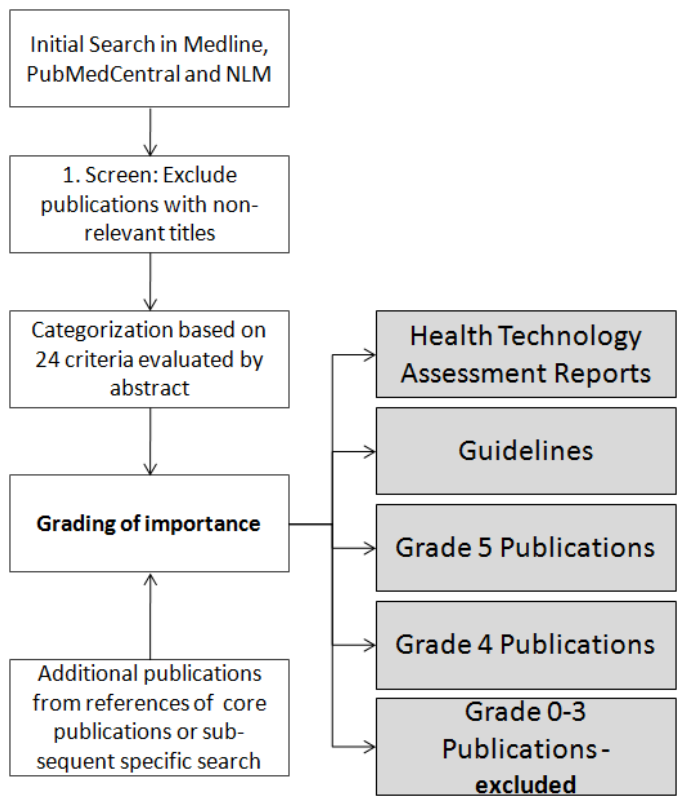

Fig. 3. Search strategy for review

The search strategy is outlined in Fig. 3 and screening and the assessment were performed by 2 evaluators. 
All titles for potential interest to the subject of 'value of bariatric surgery' were screened for relevance. This excluded approximately 30\%. Throughout the work process additional articles were added either from reference lists of core articles or as result of targeted subsequent search.

The remaining list was analyzed based on the abstracts, where available, and were then categorized. The categories were created before this second screen to help to differentiate the articles. The categories are: Economic or cost focus, HTA, Guideline, Outcomes Assessment, Geography (supportive if from Europe), Patient numbers, Length of study, Risk \& complications, Comparison of surgery vs. Drug or diet / behavioral therapy, Study Type (Prospective/Retrospective, RCT etc.) Comparisons of surgery techniques were only considered if they reported relevant overall outcomes criteria but not if the comparison seemed to be limited to 1 or few specific factors.

The remaining publications were ranked from 1 (not relevant) to 5 (highly relevant; key publication) for relevance based on the categories.

Those were graded as 5 and used for the report.

Throughout the process original articles were consulted case of doubt and availability.

\section{References}

Aasheim, Erlend T, and Torgeir T Søvik. 2011. "Global trends in body-mass index." Lancet 377 (9781) (June 4): 1916-1917; author reply 1917-1918. doi:10.1016/S01406736(11)60804-0.

Ackroyd, Roger, Jean Mouiel, Jean-Marc Chevallier, and Frederic Daoud. 2006. "Costeffectiveness and budget impact of obesity surgery in patients with type-2 diabetes in three European countries." Obesity surgery 16 (11) (November): 1488-503.

Ananthapavan, Jaithri, Marjory Moodie, Michelle Haby, and Robert Carter. 2010. “Assessing cost-effectiveness in obesity: laparoscopic adjustable gastric banding for severely obese adolescents." Surgery for Obesity and Related Diseases 6 (4) (August): 377385. doi:10.1016/j.soard.2010.02.040.

Angrisani, Luigi, Michele Lorenzo, and Vincenzo Borrelli. 2007. "Laparoscopic adjustable gastric banding versus Roux-en-Y gastric bypass: 5-year results of a prospective randomized trial." Surgery for obesity and related diseases 3 (2) (February): 127-32; discussion 132-3.

Anonymous. 1991. "NIH conference. Gastrointestinal surgery for severe obesity. Consensus Development Conference Panel." Annals of internal medicine 115 (12) (December 15): 956-61

Anselmino, Marco, Tanja Bammer, José Maria Fernández Cebrián, Frederic Daoud, Giuliano Romagnoli, and Antonio Torres. 2009. "Cost-effectiveness and budget impact of obesity surgery in patients with type 2 diabetes in three European countries(II)." Obesity Surgery 19 (11) (November): 1542-1549. doi:10.1007/s11695-009-9946-z.

Berger, Marc L, and International Society for Pharmacoeconomics and Outcomes Research. 2003. Health care cost, quality, and outcomes : ISPOR book of terms. Lawrenceville, NJ: International Society for Pharmacoeconomics and Outcomes Research. 
Bockelbrink, Angelina, Yvonne Stöber, Stefanie Roll, Cristoph Vauth, Stefan N Willich, and Johann-Matthias von der Schulenburg. 2008. "Evaluation of medical and health economic effectiveness of bariatric surgery (obesity surgery) versus conservative strategies in adult patients with morbid obesity." GMS Health Technology Assessment 4: Doc06.

Campbell, Joanna, Lisa A McGarry, Scott A Shikora, Brent C Hale, Jeffrey T Lee, and Milton C Weinstein. 2010. "Cost-effectiveness of laparoscopic gastric banding and bypass for morbid obesity." The American Journal of Managed Care 16 (7) (July): e174-187.

Cawley, John, and Chad Meyerhoefer. 2010. The medical care costs of obesity: an instrumental variables approach. Working Paper. National bureau of economic research.

CDC Diabetes Cost Effectiveness Group. 2002. “Cost-effectiveness of intensive glycemic control, intensified hypertension control, and serum cholesterol level reduction for type 2 diabetes." JAMA 287 (19) (May 15): 2542-2551. http://jama.amaassn.org/content/287/19/2542.long.

Chang, Su-Hsin, Carolyn R T Stoll, and Graham A Colditz. 2011. "Cost-effectiveness of bariatric surgery: Should it be universally available?" Maturitas 69 (3) (July): 230238. doi:10.1016/j.maturitas.2011.04.007.

Clegg, A J, J Colquitt, M K Sidhu, P Royle, E Loveman, and A Walker. 2002. “The clinical effectiveness and cost-effectiveness of surgery for people with morbid obesity: a systematic review and economic evaluation." Health technology assessment (Winchester, England) 6 (12): 1-153. http://www.hta.ac.uk/execsumm/summ612.htm.

Clegg, A, J Colquitt, M Sidhu, P Royle, and A Walker. 2003. "Clinical and cost effectiveness of surgery for morbid obesity: a systematic review and economic evaluation." International journal of obesity and related metabolic disorders 27 (10) (October): 1167-77. http://www.nature.com/ijo/journal/v27/n10/pdf/0802394a.pdf.

Craig, Benjamin M, and Daniel S Tseng. 2002. "Cost-effectiveness of gastric bypass for severe obesity." The American journal of medicine 113 (6) (October 15): 491-8.

Cremieux, Pierre-Yves, Henry Buchwald, Scott A Shikora, Arindam Ghosh, Haixia Elaine Yang, and Marric Buessing. 2008. "A study on the economic impact of bariatric surgery." The American Journal of Managed Care 14 (9) (September): 589-96. doi:10708. http://www.ajmc.com/article.cfm?ID=10708.

Dixon, J B, P Zimmet, K G Alberti, and F Rubino. 2011. "Bariatric surgery: an IDF statement for obese Type 2 diabetes." Diabetic Medicine 28 (6) (June): 628-642. doi:10.1111/j.1464-5491.2011.03306.x.

Encinosa, William E, Didem M Bernard, Dongyi Du, and Claudia A Steiner. 2009. "Recent improvements in bariatric surgery outcomes." Medical Care 47 (5) (May): 531-535. doi:10.1097/MLR.0b013e31819434c6.

Finkelstein, Eric A, Benjamin T Allaire, Somali M Burgess, and Brent C Hale. 2011. "Financial implications of coverage for laparoscopic adjustable gastric banding." Surgery for Obesity and Related Diseases 7 (3) (June): 295-303. doi:10.1016/j.soard.2010.10.011.

Finkelstein, Eric A, and Derek S Brown. 2005 (a). "A cost-benefit simulation model of coverage for bariatric surgery among full-time employees." The American journal of managed care 11 (10) (October): 641-6. 
http:/ / www.ajmc.com/article.cfm?ID=2959.

Finkelstein, Eric A, Benjamin T Allaire, Marco Dacosta Dibonaventura, and Somali M Burgess. 2011 (b). "Direct and Indirect Costs and Potential Cost Savings of Laparoscopic Adjustable Gastric Banding Among Obese Patients With Diabetes." Journal of Occupational and Environmental Medicine. doi: 10.1097/JOM.0b013e318229aae4.

Finkelstein, Eric A, Justin G Trogdon, Joel W Cohen, and William Dietz. 2009. “Annual medical spending attributable to obesity: payer-and service-specific estimates." Health Affairs (Project Hope) 28 (5) (October): w822-831. doi:10.1377/hlthaff.28.5.w822.

Finucane, Mariel M, Gretchen A Stevens, Melanie J Cowan, Goodarz Danaei, John K Lin, Christopher J Paciorek, Gitanjali M Singh, et al. 2011. "National, regional, and global trends in body-mass index since 1980: systematic analysis of health examination surveys and epidemiological studies with 960 country-years and $9 \bullet 1$ million participants." Lancet 377 (9765) (February 12): 557-567. doi:10.1016/S01406736(10)62037-5.

Flegal, Katherine M, Margaret D Carroll, Cynthia L Ogden, and Lester R Curtin. 2010. "Prevalence and trends in obesity among US adults, 1999-2008." JAMA 303 (3) (January 20): 235-241. doi:10.1001/jama.2009.2014.

http://jama.ama-assn.org/content/303/3/235.full.pdf+html.

Flum, David R, Leon Salem, Jo Ann Broeckel Elrod, E Patchen Dellinger, Allen Cheadle, and Leighton Chan. 2005. "Early mortality among Medicare beneficiaries undergoing bariatric surgical procedures." JAMA 294 (15) (October 19): 1903-8.

Frezza, Eldo E, and Mitchell S Wachtel. 2009. "The economic impact of morbid obesity." Surgical Endoscopy 23 (4) (April): 677-679. doi:10.1007/s00464-008-0325-y.

Van Gemert, W G, E M Adang, J W Greve, and P B Soeters. 1998. "Quality of life assessment of morbidly obese patients: effect of weight-reducing surgery." The American Journal of Clinical Nutrition 67 (2) (February): 197-201. http:/ / www.ajcn.org/content/67/2/197.long.

Hawkins, Simon C, Alan Osborne, Ian G Finlay, Swethan Alagaratnam, Janet R Edmond, and Richard Welbourn. 2007. "Paid work increases and state benefit claims decrease after bariatric surgery." Obesity Surgery 17 (4) (April): 434-7. doi:17608252.

Hinojosa, Marcelo W, J Esteban Varela, Dhavan Parikh, Brian R Smith, Xuan-Mai Nguyen, and Ninh T Nguyen. 2009. "National trends in use and outcome of laparoscopic adjustable gastric banding." Surgery for Obesity and Related Diseases 5 (2) (April): 150-155. doi:10.1016/j.soard.2008.08.006.

Hoerger, Thomas J, Ping Zhang, Joel E Segel, Henry S Kahn, Lawrence E Barker, and Steven Couper. 2010. "Cost-effectiveness of bariatric surgery for severely obese adults with diabetes." Diabetes Care 33 (9) (September): 1933-1939. doi:10.2337/dc10-0554.

Ikramuddin, Sayeed, David Klingman, Therese Swan, and Michael E Minshall. 2009. "Costeffectiveness of Roux-en- $Y$ gastric bypass in type 2 diabetes patients." The American Journal of Managed Care 15 (9) (September): 607-615.

Jan, Jay C, Dennis Hong, Sergio Jose Bardaro, Laura V July, and Emma J Patterson. 2007. "Comparative study between laparoscopic adjustable gastric banding and laparoscopic gastric bypass: single-institution, 5-year experience in bariatric 
surgery." Surgery for obesity and related diseases 3 (1) (January): 42-50; discussion 50-1.

Keating, Catherine L (a), John B Dixon, Marjory L Moodie, Anna Peeters, Liliana Bulfone, Dianna J Maglianno, and Paul E O'Brien. 2009. “Cost-effectiveness of surgically induced weight loss for the management of type 2 diabetes: modeled lifetime analysis." Diabetes Care 32 (4) (April): 567-574. doi:10.2337/dc08-1749.

Keating, Catherine L (b), John B Dixon, Marjory L Moodie, Anna Peeters, Julie Playfair, and Paul E O'Brien. 2009. "Cost-efficacy of surgically induced weight loss for the management of type 2 diabetes: a randomized controlled trial." Diabetes Care 32 (4) (April): 580-584. doi:10.2337/dc08-1748.

Kim, Keith, White, Vickie and Buffington, Cynthia K. 2010. "Utilization rate of bariatric surgery in an employee-based healthcare system following surgery coverage." Obesity Surgery 20 (11) (November): 1575-1578. doi:10.1007/s11695-010-0193-0.

Klarenbach, Scott, Raj Padwal, Natasha Wiebe, Maureen Hazel, Daniel Birch, Braden Manns, Shahzeer Karmali, Arya M Sharma, and Marcello Tonelli. 2010. Bariatric surgery for severe obesity: a systematic review and economic evaluation. Canada: Canadian Agency for Drugs and Technologies in Health. http://www.cadth.ca/index.php/en/hta/reportspublications/search/publication /2667.

Klein, Samuel, Arindam Ghosh, Pierre Y Cremieux, Sara Eapen, and Tamara J McGavock. 2011. "Economic impact of the clinical benefits of bariatric surgery in diabetes patients with BMI $\geq 35 \mathrm{~kg} / \mathrm{m} 2$." Obesity (Silver Spring, Md.) 19 (3) (March): 581587. doi:10.1038/oby.2010.199.

Landa, Krzysztof. 2008 Central \& Eastern European Society of Technology Assessment in Health Care.

Li, Zhaoping, Margaret Maglione, Wenli Tu, Walter Mojica, David Arterburn, Lisa R. Shugarman, Lara Hilton, et al. 2005. "Meta-Analysis: Pharmacologic Treatment of Obesity." Ann Intern Med 142 (7) (April 5): 532-546.

http://www.annals.org/cgi/content/abstract/142/7/532.

Livingston, Edward H. 2005. "Hospital costs associated with bariatric procedures in the United States." American journal of surgery 190 (5) (November): 816-20.

- - - 2010. "The incidence of bariatric surgery has plateaued in the U.S." American Journal of Surgery 200 (3) (September): 378-385. doi:10.1016/j.amjsurg.2009.11.007.

Maciejewski, Matthew L, Valerie A Smith, Edward H Livingston, Andrew L Kavee, Leila C Kahwati, William G Henderson, and David E Arterburn. 2010. "Health care utilization and expenditure changes associated with bariatric surgery." Medical Care 48 (11) (November): 989-998. doi:10.1097/MLR.0b013e3181ef9cf7.

Makary, Martin A, Jeanne M Clarke, Andrew D Shore, Thomas H Magnuson, Thomas Richards, Eric B Bass, Francesca Dominici, Jonathan P Weiner, Albert W Wu, and Jodi B Segal. 2010. "Medication utilization and annual health care costs in patients with type 2 diabetes mellitus before and after bariatric surgery." Archives of Surgery (Chicago, Ill.: 1960) 145 (8) (August): 726-731. doi:10.1001/archsurg.2010.150.

Mäklin, Suvi, Antti Malmivaara, Miika Linna, Mikael Victorzon, Vesa Koivukangas, and Harri Sintonen. 2009. "[Cost-utility of bariatric surgery in the treatment for morbid obesity in Finland]." Duodecim; Lääketieteellinen Aikakauskirja 125 (20): 22652273. 
Martin, Matthew, Alec Beekley, Randy Kjorstad, and James Sebesta. 2010. “Socioeconomic disparities in eligibility and access to bariatric surgery: a national population-based analysis." Surgery for Obesity and Related Diseases 6 (1) (February): 8-15. doi:10.1016/j.soard.2009.07.003.

National Health Expenditure Data, Department of Health \& Human Services 2011

Nguyen, Ninh T, Mahbod Paya, C Melinda Stevens, Shahrzad Mavandadi, Kambiz Zainabadi, and Samuel E Wilson. 2004. "The relationship between hospital volume and outcome in bariatric surgery at academic medical centers." Annals of surgery 240 (4) (October): 586-93; discussion 593-4. http://www.pubmedcentral.nih.gov/ articlerender.fcgi? tool=pubmed\&pubmedid $=15383786$.

Nguyen, Ninh T, Johnathan A Slone, Xuan-Mai T Nguyen, Jaimee S Hartman, and David B Hoyt. 2009. “A prospective randomized trial of laparoscopic gastric bypass versus laparoscopic adjustable gastric banding for the treatment of morbid obesity: outcomes, quality of life, and costs." Annals of Surgery 250 (4) (October): 631-641. doi:10.1097/SLA.0b013e3181b92480.

NICE Guideline CG43: Obesity guidance on the prevention, identification, assessment and management of overweight and obesity in adults and children. 29 January 2010.

O’Brien, Paul E, Tracey McPhail, Timothy B Chaston, and John B Dixon. 2006. "Systematic review of medium-term weight loss after bariatric operations." Obesity Surgery 16 (8) (August): 1032-40. doi:10.1381/096089206778026316.

Ojo, Peter, and Elmer Valin. 2009. “Cost-effective restrictive bariatric surgery: laparoscopic vertical banded gastroplasty versus laparoscopic adjustable gastric band." Obesity Surgery 19 (11) (November): 1536-1541. doi:10.1007/s11695-008-9771-9.

Ostbye, Truls, John M Dement, and Katrina M Krause. 2007. "Obesity and workers' compensation: results from the Duke Health and Safety Surveillance System." Archives of Internal Medicine 167 (8) (April 23): 766-73. doi:167/8/766.

Padwal, Raj, Scott Klarenbach, Natasha Wiebe, Maureen Hazel, Daniel Birch, Shahzeer Karmali, Arya M Sharma, Braden Manns, and Marcello Tonelli. 2011. "Bariatric Surgery: A Systematic Review of the Clinical and Economic Evidence." Journal of General Internal Medicine (May 3). doi:10.1007/s11606-011-1721-x.

Palmer, Andrew J, Stéphane Roze, William J Valentine, Michael E Minshall, Volker Foos, Francesco M Lurati, Morten Lammert, and Giatgen A Spinas. 2004a. "The CORE Diabetes Model: Projecting long-term clinical outcomes, costs and cost-effectiveness of interventions in diabetes mellitus (types 1 and 2) to support clinical and reimbursement decision-making." Current Medical Research and Opinion 20 Suppl 1 (August): S5-26. doi:10.1185/030079904X1980.

- - - 2004b. "Validation of the CORE Diabetes Model against epidemiological and clinical studies." Current Medical Research and Opinion 20 Suppl 1 (August): S27-40. doi:10.1185/030079904X2006.

Paxton, James H, and Jeffrey B Matthews. 2005. "The cost effectiveness of laparoscopic versus open gastric bypass surgery." Obesity surgery 15 (1) (January): 24-34.

Pendergast, Karen, Anne Wolf, Beth Sherrill, Xiaolei Zhou, Louis J Aronne, Ian Caterson, Nicholas Finer, et al. 2010. "Impact of waist circumference difference on health-care cost among overweight and obese subjects: the PROCEED cohort." Value in Health 13 (4) (July): 402-410. doi:10.1111/j.1524-4733.2009.00690.x. 
Perry, Cynthia D, Matthew M Hutter, Daniel B Smith, Joseph P Newhouse, and Barbara J McNeil. 2008. "Survival and changes in comorbidities after bariatric surgery." Annals of Surgery 247 (1) (January): 21-7. doi:10.1097/SLA.0b013e318142cb4b.

Picot, J, J Jones, J L Colquitt, E Gospodarevskaya, E Loveman, L Baxter, and A J Clegg. 2009. "The clinical effectiveness and cost-effectiveness of bariatric (weight loss) surgery for obesity: a systematic review and economic evaluation." Health Technology Assessment (Winchester, England) 13 (41) (September): 1-190, 215-357, iii-iv. doi:10.3310/hta13410.

Powers, Kinga A, Scott T Rehrig, and Daniel B Jones. 2007. "Financial impact of obesity and bariatric surgery." The Medical clinics of North America 91 (3) (May): 321-38, ix.

Salem, Leon, Allison Devlin, Sean D Sullivan, and David R Flum. 2008. "Cost-effectiveness analysis of laparoscopic gastric bypass, adjustable gastric banding, and nonoperative weight loss interventions." Surgery for Obesity and Related Diseases 4 (1): 26-32. doi:S1550-7289(07)00672-7.

Salgado Júnior, Wilson, Karoline Calfa Pitanga, José Sebastião dos Santos, Ajith Kumar Sankarankutty, Orlando de Castro e Silva Jr, and Reginaldo Ceneviva. 2010. "Costs of bariatric surgery in a teaching hospital and the financing provided by the Public Unified Health System." Acta Cirúrgica Brasileira / Sociedade Brasileira Para Desenvolvimento Pesquisa Em Cirurgia 25 (2) (April): 201-205.

Sampalis, John S, Moishe Liberman, Stephane Auger, and Nicolas V Christou. 2004. "The impact of weight reduction surgery on health-care costs in morbidly obese patients." Obesity surgery 14 (7) (August): 939-47.

Shao, Qin, and Khew-Voon Chin. 2011. "Survey of American food trends and the growing obesity epidemic." Nutrition Research and Practice 5 (3) (June): 253-259. doi:10.4162/nrp.2011.5.3.253.

http://www.ncbi.nlm.nih.gov/pmc/articles/PMC3133759/pdf/nrp-5-253.pdf.

Hiroiwa, Takeru, Yoon-Kyoung Sung, Takashi Fukuda, Hui-Chu Lang, Sang-Cheol Bae, and Kiichiro Tsutani. 2010. "International survey on willingness-to-pay (WTP) for one additional QALY gained: what is the threshold of cost effectiveness?" Health Economics 19 (4) (April 1): 422-437. doi:10.1002/hec.1481

Snow, Vincenza, Patricia Barry, Nick Fitterman, Amir Qaseem, Kevin Weiss, and for the Clinical Efficacy Assessment Subcommittee of the American College of Physicians*. 2005. "Pharmacologic and Surgical Management of Obesity in Primary Care: A Clinical Practice Guideline from the American College of Physicians." Ann Intern Med 142 (7) (April 5): 525-531. http:// www.annals.org/cgi/reprint/142/7/525.pdf.

Villamizar, Nestor, and Aurora D Pryor. 2011. "Safety, effectiveness, and cost effectiveness of metabolic surgery in the treatment of type 2 diabetes mellitus." Journal of Obesity 2011: 790683. doi:10.1155/2011/790683. 


\section{ADVANCED}

BARIATRIC AND

METABOLIC SURGERY

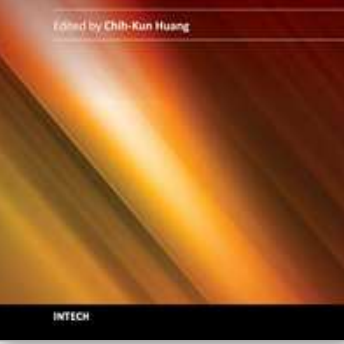

\section{Advanced Bariatric and Metabolic Surgery}

Edited by Dr. Chih-Kun Huang

ISBN 978-953-307-926-4

Hard cover, 326 pages

Publisher InTech

Published online 29, February, 2012

Published in print edition February, 2012

Bariatric surgery has gained importance in the last 20 years because of the high prevalence of global obesity, and the vast understating of the physiological and pathological aspects of obesity and associated metabolic syndromes. This book has been written by a number of highly outstanding authors and pioneering bariatric surgeons from all over the world. The intended audience for this book includes all medical professionals involved in caring for bariatric patients. The chapters cover the choice of operation, preoperative preparation including psychological aspect, postoperative care and management of complication. It also extends to concept and result of metabolic surgery and scarless bariatric surgery.

\section{How to reference}

In order to correctly reference this scholarly work, feel free to copy and paste the following:

Anke-Peggy Holtorf, Harald Rinde, Frederic Rupprecht, Henry Alder and Diana Brixner (2012). The Economic Impact of Bariatric Surgery, Advanced Bariatric and Metabolic Surgery, Dr. Chih-Kun Huang (Ed.), ISBN: 978953-307-926-4, InTech, Available from: http://www.intechopen.com/books/advanced-bariatric-and-metabolicsurgery/the-economic-impact-of-bariatric-surgery

\section{INTECH}

open science | open minds

\section{InTech Europe}

University Campus STeP Ri

Slavka Krautzeka 83/A

51000 Rijeka, Croatia

Phone: +385 (51) 770447

Fax: +385 (51) 686166

www.intechopen.com

\section{InTech China}

Unit 405, Office Block, Hotel Equatorial Shanghai

No.65, Yan An Road (West), Shanghai, 200040, China

中国上海市延安西路65号上海国际贵都大饭店办公楼405单元

Phone: +86-21-62489820

Fax: +86-21-62489821 
(C) 2012 The Author(s). Licensee IntechOpen. This is an open access article distributed under the terms of the Creative Commons Attribution 3.0 License, which permits unrestricted use, distribution, and reproduction in any medium, provided the original work is properly cited. 